\title{
Assessment of Sharp Injuries among Cameroonian Dental Professionals
}

Authors: Agbor M.A. ${ }^{1}$, Azodo C.C. ${ }^{2}$, Affiliations: 1- Dental Department, Nkwen Baptist Health Centre, Bamenda, Cameroon 2- Department of Periodontics, University of Benin Teaching Hospital, Nigeria, Corresponding author: Dr Agbor Michael Ashu, Nkwen Baptist Health Centre, P 0 Box 1, Bamenda, Cameroon. Email: agborasm@yahoo.com, clementazodo@yahoo.com Phone: +237 77170167

\section{Abstract}

Objective

To assess the prevalence of sharp injury among Cameroonian dental professionals.

\section{Materials and Methods}

A cross-sectional study of 41 dental professionals recruited from 4 out of 10 provinces in Cameroon was conducted in the second half of 2009. A self-administered questionnaire was used to capture information on demography, nature, frequency and causes of sharp injury, post-exposure prophylaxis practice and methods of sharps disposal.

Results

Thirty-nine dental professionals (95.1\%) had experienced sharp injury with $35.9 \%$ being once in the preceding 12 months. Needlestick was the most common sharp injury experienced by the respondents. Most of the injuries occurred during recapping of the needle. Activity during which injuries occurred was not significantly associated with type of practice. Twenty three (59.0\%) respondents received post-exposure prophylaxis after sustaining sharp injury.

Proper disposal of sharps in a special container was observed by 35 (85.4\%) of the respondents.

\section{Conclusion}

The prevalence of sharp injuries among Cameroonian dental professionals was high. This justifies an urgent need for concerted effort to reduce sharp injuries in Cameroon dental practices through a comprehensive sharp injury prevention program including work place safety, employee training on guidelines adherence, safe recapping and disposal systems.

\section{Introduction}

Percutaneous exposure to blood and body fluid following sharps injury is a common occupational adverse event that increases the risk of transmission of bloodborne pathogens like Hepatitis B, Hepatitis C and HIV (1). The psychological, medical, career and financial consequences of sharp injuries have been previously documented $(2,3)$.

Although sharp injuries among dental professionals have been explored in several industrialized nations, data are less available from developing countries. A study of hospital-based dental professionals in United States of America revealed that about a quarter of percutaneous injury were due to anaesthetic syringe injury occurring during activity and after needle use (4). Another study among Minnesota dental practitioners showed that dental surgery assistants and hygienists reported numerous injuries associated with recapping of needles (5). Among Turkish nurses, 22.4\% experienced sharps injuries of which $63.6 \%$ were needlestick exposures (6). In Nigeria, a study amongst clinical dental students revealed that $58.8 \%$ of the students have had at least one occupational exposure with most occurring during manual tooth cleaning (7). There also existed variation in the frequency among dental professionals with dentists leading the pack in some $(4,8)$ and dental nurses in others (9).

Previous studies suggest that about half of all dentists report a recent needlestick and sharps injuries in both the United Kingdom (10) and in Thailand (11). The most common "sharps" injuries among dentists continue to arise from needles and drilling instruments, such as burs (10-12).

The objective of the study was to assess the prevalence of sharp injury among Cameroonian dental professionals.

\section{Materials And Methods}

A cross-sectional study of 41 dental professionals recruited from 4 out of 10 provinces in Cameroon was conducted in the second half of 2009. A self-administered questionnaire was used to collect information on demography, nature, frequency and causes of sharps injury, post-exposure prophylaxis practice and methods 
of sharps disposal. Ethical clearance to carry out the study was obtained from the respective provincial organs of the Cameroonian Ministry of Public Health in the four provinces. Informed consent was obtained from the participants after being informed of the objective of the study and assured of strict confidentiality of their responses. Participation was voluntary and no incentive was declared. Epi-info version Epi 16 was used for data analysis. Test for significance was done using Chi square. P $\leq 0.05$ was considered significant. The results were presented in tabular forms.

\section{Results}

The respondents were mostly male and in the 31-40 years age group. Those working in government owned dental units comprised $39.0 \%$ while $70.7 \%$ worked in dental clinics located in the urban centers (Table 1). Injuries from sharp objects were caused by injection needles (41.0\%), hand instruments (15.4\%), broken glasses (12.8\%), burs (10.3\%) and other instruments (20.5\%) (Table 2). Most workers (35.9\%) sustained injuries once a year, $28.2 \%$ once every 6 months, $17.9 \%$ every month and $5.1 \%$ every week (Table 3). Majority (41.0\%) of the sharp injuries occurred during dental procedures and $11(28.2 \%)$ occurred during the recapping of needle. The activity during which sharp injury occurred was not related to the type of practice ( $\mathrm{P}=0.43$ ) (Table 4). Most of the respondents who sustained injuries (59.0\%) received post-exposure prophylaxis (Table $5)$. The mode of disposal of sharps for most respondents (85.4\%, n 35) was into special containers (Table 6).

\section{Discussion}

Sharps injuries potentially expose workers to deadly viruses and other bloodborne pathogens. The prevalence of sharps injury was $95.1 \%$ and a high frequency of multiple exposures was evident in this study. The rates in this study are comparable to those from Nigeria (13) but lower than those from South Africa (14). Frequent uses

\begin{tabular}{lll}
$\begin{array}{l}\text { Characteristics } \\
\text { Age (years) }\end{array}$ & Frequency (no.) & Percent (\%) \\
\hline$<30$ & 8 & 19.5 \\
\hline $31-40$ & 18 & 43.9 \\
\hline $41-50$ & 9 & 21.9 \\
\hline$>50$ & 6 & 14.6 \\
\hline Sex & & \\
\hline Male & 24 & 58.5 \\
\hline Female & 17 & 41.1 \\
\hline Status & & \\
\hline Dentist & 13 & 31.7 \\
\hline Dental auxiliaries & 28 & 68.3 \\
\hline Type of practice & & 39.0 \\
\hline Government & 16 & 26.8 \\
\hline Private & 11 & 24.1 \\
\hline Missionary & 14 & 70.7 \\
\hline Location of the practice & & 29.3 \\
\hline Urban & 29 & 100.0 \\
\hline Rural & 12 & \\
\hline Total & 41 & \\
\hline
\end{tabular}

Table 1: Demographic Characteristics of the Respondents

\begin{tabular}{lll} 
Nature of injury & Frequency (no.) & Percent (\%) \\
\hline Injection needles & 16 & 41.0 \\
\hline Sharp hand instruments like probes & 6 & 15.4 \\
\hline Broken glasses like dental cartridges & 5 & 12.8 \\
\hline Burs & 4 & 10.3 \\
\hline Others & 8 & 20.5 \\
\hline Total & 39 & 100.0 \\
\hline
\end{tabular}

Table 2: Nature of Sharp Injuries Experienced by the Respondents of sharps in oral healthcare delivery and restricted narrow field of surgery presumably contribute to the high rate of occupational exposure. Consequently, policy generation to address this risk with its attendant clinical, emotional, social and financial consequences is recommended.

The injection needle constituted the majority of sharps injuries in this study, similar to the findings among Nigerian dentists (15). Needle safety is also a concern in other African countries and medical specialties. In the previous study in Nigeria, $90.3 \%$ of Gynaecological 


\section{Assessment of Sharp Injuries among Cameroonian Dental Professionals}

\section{Agbor M.A., Azodo C.C.}

\begin{tabular}{lll}
\hline How often is the injury & Frequency (no.) & Percent (\%) \\
\hline Once in a year & 14 & 35.9 \\
\hline Every week & 2 & 5.1 \\
\hline Once in 6 months & 11 & 28.2 \\
\hline Once a month & 7 & 17.9 \\
\hline Unspecified & 5 & 12.8 \\
\hline Total & 39 & 100.0 \\
\hline
\end{tabular}

Table 3: Frequency of Sharp Injuries among the Respondents

\begin{tabular}{llllll}
\multicolumn{6}{c}{ Activity } \\
\hline Type of Practice & $\begin{array}{l}\text { During } \\
\text { dental } \\
\text { procedure }\end{array}$ & $\begin{array}{l}\text { During } \\
\text { recapping } \\
\text { needle }\end{array}$ & $\begin{array}{l}\text { During } \\
\text { washing } \\
\text { of instruments }\end{array}$ & $\begin{array}{l}\text { When } \\
\text { disposing }\end{array}$ & Total \\
\hline instruments \\
\hline Covernmental & $5(31.3)$ & $7(43.8)$ & $2(12.5)$ & $2(12.5)$ & $16(100.0)$ \\
\hline Private & $5(50.0)$ & $3(30.0)$ & $1(10.0)$ & $1(10.0)$ & $10(100.0)$ \\
\hline Total & $16(41.0)$ & $11(28.2)$ & $\mathbf{8 ( 2 0 . 5 )}$ & $\mathbf{4 ( 1 0 . 3 )}$ & $39(100.0)$ \\
\hline
\end{tabular}

$X 2=8.05, d f=8, P=0.42825$

Table 4: Relationship Between Type of Practice and Activities during which the Respondents Experienced Sharp Injuries

\begin{tabular}{lll} 
Prophylaxis & Frequency (no.) & Percent (\%) \\
\hline Yes & 23 & 59.0 \\
\hline No & 16 & 41.0 \\
\hline Total & 39 & 100 \\
\hline
\end{tabular}

Table 5: Post-Exposure Prophylaxis after Sustaining Sharp Injury among the Respondents

\begin{tabular}{lll} 
Mode of disposal of sharps & Frequency (no.) & Percent (\%) \\
\hline In a special container made for sharps & 35 & 85.4 \\
\hline I discard immediately I use them & 4 & 9.8 \\
\hline In a waste bucket with other solid wastes & 2 & 4.9 \\
\hline Total & 41 & 100.0 \\
\hline
\end{tabular}

Table 6: Mode of Sharps Disposal in the Clinic among Respondents

surgeons experienced needlestick injuries in their workplace (2). Injuries with sharps can occur during both use in treatment (dislodged during manipulation) and after use (during cleanup or disposal). However, strict adherence to guideline on standard precaution reduces the occurance of sharp injury during healthcare delivery. In this study, majority of the injuries occurred during dental procedures and after while recapping the needle, signifying poor work practices and low adherence to standard precautions. Needlestick injuries occurring while giving injections remain a significant concern as some residual body fluid in the needle is usually introduced into the puncture site. In Minnesota physicians' offices, needlestick injuries occurred more in small offices especially during blood drawing and recapping of needle (16). In our study, there was no significant variability in activity during which sharps injury occurred with the type of dental practice whether public, missionary or private.

More than half of respondents with sharps injuries were given post-exposure prophylaxis. This is higher than $9.2 \%$ of the gynecological surgeons in Nigeria (2) and the twothirds of dentists working in private practice in Durban who did not follow any specific protocol after injury (14).

Sharps disposal containers are specially designed containers into which used needles and other medical-waste sharps are discarded. Good sharps disposal practice is essential to prevent accidental inoculation with blood or body fluids (17). Contributory factors to non compliance with appropriate sharp disposal including lack of sharps container, forgetfulness or lack of motivation or training are abound in developing countries. In this study, the disposal after use was satisfactory as most of the respondents (85.4\%) disposed their sharps in special containers. The group (4.9\%) who disposed sharps in the waste baskets with other solid waste is a target for intervention. This study finding was higher than $47 \%$ reported among dental practitioners in Khartoum, Sudan, who stored sharp items in closed containers (18). In North Jordan, 31.8\% of general dental practitioners in the private sector had special containers for sharps disposal (19). Provision of sharps container and education are needed in dental clinics in Cameroon to ensure total compliance with sharps disposal in sealed sharps containers. 


\section{Conclusion}

The frequency and prevalence of sharps injuries among Cameroonian dental professionals was high. This justifies a need for concerted effort to reduce sharps injuries in Cameroon through comprehensive sharps injury prevention program like improved organization of work, employee training, recommended guidelines, safe recapping procedures, effective disposal systems, surveillance programs and improved equipment design.

\section{References}

1. Pietrabissa A, Merigliano S, Montorsi M, et al. Reducing the occupational risk of infections for the surgeon: multicentric national survey on more than 15,000 surgical procedures. World J Surg. 1997; 21(6):573-8.

2. Efetie ER, Salami HA. Prevalence of, and attitude towards, needle-stick injuries by Nigerian gynaecological surgeons. Niger J Clin Pract. 2009; 12(1):34-6.

3. Mehta A, Rodrigues C, Ghag S, et al. Needlestick injuries in a tertiary care centre in Mumbai, India. J Hosp Infect. 2005; 60(4):368-73.

4. Cleveland JL, Barker LK, Cuny EJ, et al. National surveillance system for health care workers group. Preventing percutaneous injuries among dental health care personnel. J Am Dent Assoc. 2007; 138(2):169-78.

5. Hastreiter RJ, Roesch MH, Heckert KA, et al. Infection control practices and beliefs of Minnesota dental hygienists and dental assistants. J Dent Hyg. 1990; 64(8):37681.

6. Kosgeroglu N, Ayranci U, Vardareli E, Dincer S. Occupational exposure to hepatitis infection among Turkish nurses: frequency of needle exposure, sharps injuries and vaccination. Epidemiol Infect. 2004; 132(1):27-33.

7. Sofola OO, Folayan MO, Denloye OO, et al. Occupational exposure to bloodborne pathogens and management of exposure incidents in Nigerian dental schools. J Dent Educ. $2007 ; 71(6)$ : 832-837.
8. Shah SM, Merchant AT, Dosman JA. Percutaneous injuries among dental professionals in Washington State. BMC Public Health. 2006; 6:269.

9. Qudeimat MA, Farrah RY, Owais AI. Infection control knowledge and practices among dentists and dental nurses at a Jordanian University Teaching Center. Am J Infect Control. 2006; 34(4):218-22.

10. Porter K, Scully C, Theyer Y, Porter S. Occupational injuries to dental personnel. J Dent. 1990; 18(5):258-62.

11. Chowanadisai S, Kukiattrakoon B, Yapong B, et al. Occupational health problems of dentists in southern Thailand. Int Dent J. 2000; 50(1):36-40.

12. Leggat PA, Smith DR. Prevalence of percutaneous exposure incidents amongst dentists in Queensland. Aust Dent J. 2006; 51(2):158-61.

13. Odeyemi KA, Onifade KA, Onifade EU. Needle Stick/ Sharp injuries among doctors and nurses at the Lagos University Teaching Hospital. NQJHM 2005; 15(2): 5054.

14. Yengopal V, Naidoo S, Chikte UM. Infection control among dentists in private practice in Durban. SADJ. 2001; 56(12):580-4.

15. Utomi IL. Percutaneous injuries in Nigerian dentists. NQJHM 2003; 13(3-4): 65 -68

16. Thurn J, Willenbring K, Crossley K. Needlestick injuries and needle disposal in Minnesota physicians' offices. Am J Med. 1989; 86(5):575-9.

17. McCarthy GM, Koval JJ, MacDonald JK. Occupational injuries and exposures among Canadian dentists: the results of a national survey. Infect Control Hosp Epidemiol. 1999; 20(5):331-6.

18. Elkarim IA, Abdulla ZA, Yahia NA, et al. Basic infection control procedures in dental practice in Khartoum-Sudan. Int Dent J. 2004; 54(6):413-7.

19. Al-Omari MA, Al-Dwairi ZN. Compliance with infection control programs in private dental clinics in Jordan. J Dent Educ. 2005; 69(6):693-8. 